\section{RETROGRADE BRAIN PERFUSION BEYOND THE VENOUS VALVES}

\section{Hemodynamics and intracellular pH mapping}

Twenty-one dogs (group 1) had retrograde brain perfusion for 90 minutes through the sagittal sinus and superior vena cava with pressure-regulated cardiopulmonary bypass, and 10 dogs (group 2) had 60 minutes of circulatory arrest with an additional 30 -minute evaluation of brain slices, both at $20^{\circ} \mathrm{C}$. In group 1 , cerebral blood flow determined by laser flowmetry was $8.98 \pm 2.02 \mathrm{ml} / 100 \mathrm{gm} / \mathrm{min}$ with a driving pressure of $29.69 \pm 9.92 \mathrm{~mm}$ $\mathrm{Hg}$ during the retrograde perfusion, whereas it was $0.85 \mathrm{ml} / 100 \mathrm{gm} / \mathrm{min}$ during solitary perfusion through the superior vena cava. Retrograde cerebral vascular resistance was slightly higher than the antegrade resistance. Neutral red stain was given intraperitoneally as an intracellular pH indicator. Regional intracellular pH was calculated from photoabsorption at 440 and $535 \mathrm{~nm}$ with the use of color transparency photographs of the brain and spinal cord slices taken after retrograde cerebral perfusion in group 1 and after circulatory arrest in group 2 . The $\mathrm{pH}$ mapping showed that the retrograde brain perfusion maintained the $\mathrm{pH}$ within 6.77 to 7.14 , whereas the cerebral $\mathrm{pH}$ decreased to 6.24 to 6.43 at 60 minutes of circulatory arrest and further decreased to 5.81 to 6.22 at 90 minutes. The pH after the retrograde brain perfusion was significantly higher than the pH after circulatory arrest in the entire brain and the spinal cord. We conclude that the brain is protected when perfused retrogradely beyond the venous valves with a driving pressure above $20 \mathrm{~mm} \mathrm{Hg}$. (J THORAC Cardiovasc Surg 1996;111:36-44)

Takao Watanabe, MD, Yoshiyuki Iijima, MD, Kazuo Abe, MD, Hiromasa Abe, MD, Hiroyuki Saito, MD, Yoshiki Naruke, MD, and Masahiko Washio, MD, Yamagata, Japan
$\mathrm{R}_{\mathrm{t} \text { te }}^{\mathrm{e}}$ etrograde cerebral perfusion, used initially to treat massive air embolisms, ${ }^{1,2}$ is broadly used in aortic arch procedures as an adjunct to circulatory arrest or an alternative to selective cerebral perfusion during profound hypothermia. ${ }^{3-9}$

Although this simple technique is expected to perfuse and protect the brain for 90 minutes during profound hypothermia, ${ }^{4,-12}$ the physiologic aspects of retrograde circulation in the brain have been left unexplored. Recent favorable clinical results of the retrograde perfusion may indicate that venous

From the Second Department of Surgery, Yamagata University School of Medicine, Iida-Nishi, 990-23, Yamagata, Japan.

Supported by a Grant-in-Aid for Scientific Research, 1992-1993.

Received for publication Dec. 2, 1994.

Accepted for publication March 28, 1995.

Address for reprints: Takao Watanabe, MD, The Second Department of Surgery, Yamagata University School of Medicine, Iida-Nishi2-2-2, Yamagata 990-23, Japan.

Copyright (c) 1996 by Mosby-Year Book, Inc.

$0022-5223 / 96 \$ 5.00+0 \quad \mathbf{1 2 / 1 / 6 5 2 0 4}$ valves in human jugular veins, if present, rarely block the retrograde blood flow to the human brain. ${ }^{6-9}$ However, experimental data accumulated until now fail to show the relationship between the driving pressure and the cerebral blood flow (CBF) during retrograde perfusion because the competent venous valves in other mammalian cerebral circulation systems usually obstruct blood flow to the brain if only the superior vena cava (SVC) or the cervical veins are perfused and the valves in jugular veins are not disrupted. ${ }^{8,10-13}$ The data also fail to show whether the entire brain is uniformly perfused and protected by the retrograde brain perfusion.

We have developed an experimental model of retrograde perfusion in core-cooled dogs that can perfuse the brain beyond the venous valves without disrupting them. The canine brain, in group 1 , was perfused retrogradely through the sagittal sinus and the SVC for 90 minutes, with the use of an automatic pressure control circuit incorporated in retrograde cardiopulmonary bypass (CPB). We continuously measured the CBF with a laser flowmeter and 
the actual driving pressure between the sagittal sinus and the aorta. To determine whether the entire brain and the spinal cord were protected by the retrograde perfusion, we mapped the intracellular $\mathrm{pH}$ of the entire brain slices and the thoracic spinal cord, after 90 minutes of retrograde brain perfusion in group 1 , at $20^{\circ} \mathrm{C}$, and $\mathrm{pH}$ was measured by means of a photometric method with a vital dye. This method, established by LaManna, ${ }^{1.4-17}$ was modified to measure the $\mathrm{pH}$ in the entire brain at $20^{\circ} \mathrm{C}$. As the control, dogs of group 2 had 60 minutes of profoundly hypothermic circulatory arrest. We also mapped their intracellular $\mathrm{pH}$ of the entire brain and the thoracic spinal cord afterwards for 30 minutes.

\section{Material and methods}

Thirty-one mongrel dogs, 8.6 to $12 \mathrm{~kg}$, were used for this study. Twenty-one were in group 1 , which involved retrograde brain perfusion, and 10 were in group 2, which involved circulatory arrest alone. Among 21 dogs of group 1, 12 had moderate-pressure retrograde perfusion (20 to $25 \mathrm{~mm} \mathrm{Hg}$, subgroup 1-A) and the remaining nine had high-pressure retrograde perfusion (above $35 \mathrm{~mm} \mathrm{Hg}$, subgroup 1-B). They received humane care in compliance with the "Principles of Laboratory Animal Care" formulated by the National Society for Medical Research and the "Guide for the Care and Use of Laboratory Animals" prepared by the Institute of Laboratory Animal Resources and published by the National Institutes of Health (NIH publication No. 85-23, revised 1985).

Animal preparation and CPB. The dogs were anesthesized with pentobarbital sodium (intravenously, $25 \mathrm{mg} /$ $\mathrm{kg}$ ), and their lungs were ventilated mechanically with room air after tracheal intubation. Anesthesia was maintained by addition of pentobarbital sodium $(6 \mathrm{mg} / \mathrm{kg} /$ hour $)$ until $\mathrm{CPB}$ was instituted. Catheters $(15 \mathrm{~cm}$ in length) were inserted into the abdominal aorta and inferior vena cava (IVC) through the femoral artery and veins for pressure monitoring. A section of the right cranium was removed $(3 \times 4 \mathrm{~cm})$. In group 1 , the posterior portion of the sagittal sinus was exposed by extending the craniotomy. A flow probe (Type CS; Advance Co., Ltd., Tokyo, Japan) was introduced into the subdural space through a $6 \mathrm{~mm}$ durotomy made in the posterior part of the craniotomy. The tip of the probe was set to contact the cerebral cortex of the gyrus in the anterior portion of the parietal lobe. The cerebral vasculature was avoided by inspecting the position of the probe through the dura mater and by confirming that the recorded $\mathrm{CBF}$ was not excessive and not pulsatile. This probe was connected to a laser flowmeter and a recorder (Laser Flow Meter ALF21 and ALF R1; Advance) to measure continuously the cerebral tissue blood flow.

A small laparotomy was made in both groups. Neutral red stain $(1.5 \mathrm{gm} / 200 \mathrm{ml}$ of saline solution) was given intraperitoneally as an indicator of cerebral intracellular $\mathrm{pH}$. After a right thoracotomy and heparinization (4 $\mathrm{mg} / \mathrm{kg}$ ), the ascending aorta was cannulated with a metal- tipped cannula $(5.3 \mathrm{~mm}$, with an additional $2.5 \mathrm{~mm}$ side hole; Sarns, Ann Arbor, Mich.), and both venae cavae were also cannulated (22F for the SVC and $24 \mathrm{~F}$ for the IVC). An oxygenator (Menox AL 4000; Kurare, Okayama, Japan) and an original hard shell reservoir were used. The circuit was primed with $350 \mathrm{ml}$ of saline solution, $40 \mathrm{ml}$ of $7 \%$ sodium bicarbonate, and $60 \mathrm{ml}$ of $20 \%$ mannitol. The arterial line of the circuit had two branches. The proximal branch was used to regulate the intraluminal pressure, and the distal branch was used to send the oxygenated blood to the sagittal sinus during the hypothermic retrograde brain perfusion. CPB was instituted for 45 minutes with a perfusion flow rate of 100 $\mathrm{ml} / \mathrm{kg} / \mathrm{min}$ to lower the nasopharyngeal and rectal temperature to $16^{\circ} \pm 1^{\circ} \mathrm{C}$, in both groups.

Retrograde brain perfusion (group 1). Twenty-one dogs were subjected to retrograde brain perfusion. After the core cooling, the perfusion was discontinued for a short period. The arterial and venous lines of the CPB circuit were exchanged. The sagittal sinus was cannulated posteriorly with a 14-gauge venous catheter for perfusion and anteriorly with a 24 -gauge catheter for pressure monitoring. The former catheter was connected to the distal branch of the CPB circuit. The proximal branch of the circuit was extended to an open end, from where the excess blood issued and returned back to the reservoir (Fig. 1). The perfusion pressure was easily controlled by altering the height of this open end.

Within 7 minutes, retrograde perfusion was commenced. For the first 5 minutes, the SVC alone was perfused. Then, simultaneous perfusion through the sagittal sinus and the SVC was started and continued for 90 minutes. The IVC cannula was clamped. The SVC tape proxymal to the azygos vein and the IVC tape were fastened. The azygos vein was ligated at the level of the IVC to maintain the high pressure in the azygos vein. Blood was drained out from the aortic cannula throughout the retrograde perfusion.

After the retrograde perfusion was completed, all the blood was drained, the dura mater was opened, and a photograph of the cerebral surface was taken. Then the whole brain was removed and sliced for examination of regional changes in intracellular $\mathrm{pH}$ and water content. The thoracic (T4-9) spinal cord was also removed for the same examination.

Pressure/CBF study. Among these 21 dogs (group 1), 12 were perfused retrogradely with the pressure in the sagittal sinus within the moderate range of 20 to $35 \mathrm{~mm}$ $\mathrm{Hg}$ (subgroup 1-A). The remaining nine dogs (subgroup 1-B) had high-pressure retrograde perfusion, where the pressure in the sagittal sinus and the SVC was elevated from $25 \mathrm{~mm} \mathrm{Hg}$ to above $35 \mathrm{~mm} \mathrm{Hg}$.

For further clarification of the antegrade and retrograde CBF response to perfusion pressure, incremental decrease pressure/CBF studies were performed in 15 dogs (group 1: six dogs of subgroup 1-A and all nine dogs of subgroup 1-B). Brief antegrade low-flow perfusions (50, 25 , and $12.5 \mathrm{ml} / \mathrm{kg} / \mathrm{min}$ ) were added at the end of the core cooling. The end of the retrograde perfusion, the height of the open end in the CPB circuit, and the pump flow rate were changed simultaneously to measure the CBF obtained by different retrograde perfusion pressures. Every 


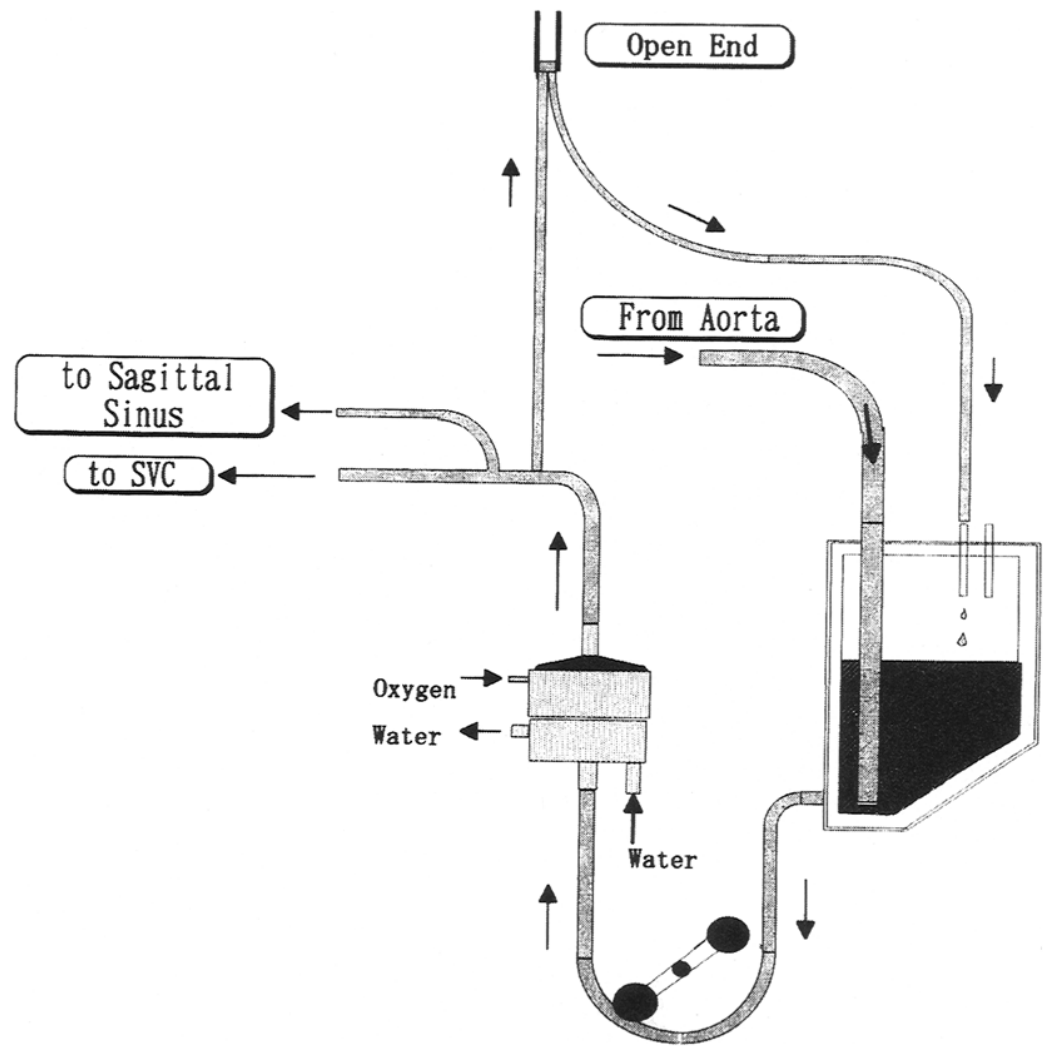

Fig. 1. Pressure-regulated circuit for retrograde brain perfusion through sagittal sinus and the SVC.

incremental change of perfusion was continued for 3 to 5 minutes until the CBF value was stabilized.

Circulatory arrest (group 2). Ten dogs, who received intraperitoneal administration of neutral red stain, were core cooled and subjected to total circulatory arrest. After 50 to 60 minutes of circulatory arrest, the whole brain and the spinal cord were removed, sliced to $5 \mathrm{~mm}$ thick pieces, and placed in an acrylate box. They were exposed to an anoxic atmosphere with the box being blown through with $1 \mathrm{~L} / \mathrm{min}$ of moist nitrogen gas for 30 minutes at $20^{\circ} \mathrm{C}$. Color transparency photographs of the brain and spinal cord slices were taken at the beginning and at the end of this 30-minute period, thus representing 60 and 90 minutes of "circulatory arrest." Intracellular pH and the water content were measured.

Measurements. Cerebral tissue blood flow was measured and recorded continuously by means of laser photometry. The pressure was recorded in the aorta, sagittal sinus, and IVC. The removed whole brain and the thoracic spinal cord were weighed immediately after the procedures and, after 10 days, dried at $75^{\circ} \mathrm{C}$.

Blood was sampled from the CPB circuit and analyzed for $\mathrm{pH}$, oxygen and carbon dioxide tensions, base excess (ABL-300; Radiometer, Copenhagen, Denmark), hematocrit value, and glucose and lactate contents (YSI 2300 STAT; Yellow Spring Instrument, Yellow Spring, Ohio).

Brain intracellular $\mathrm{pH}$ was measured photometrically, according to the method of LaManna et al. ${ }^{14-17}$ Neutral red stain is bound to mitochondria in neuronal cells within 30 minutes of intraperitoneal administration. Intracellular $\mathrm{pH}$ determines the photospectrum absorption curve of the dye. Color photographs of the cerebral surface, all brain slices, and thoracic spinal cord were taken in transparency films $(1 / 8$ second, F = 11, RD135; Fuji Photo Film, Kanagawa, Japan). Using a two-wave length color spot scanner (CS-9000; Shimadzu, Kyoto, Japan), we measured the absorption spectrum in each area in the color transparency photographs of the specimens, where the beam size was set at $0.4 \times 0.4 \mathrm{~mm}$. The absorption was measured at two absorption peaks of 440 $\mathrm{nm}$ and $535 \mathrm{~nm}$. Blank photoabsorption was also measured with an unstained brain to minimize the effects of hemoglobin in the specimens, the color films used, and photoabsorptions by the tissue itself. The raw blanks of the corresponding parts were corrected in proportion with the absorption of the stained brain at $440 \mathrm{~nm}$ because the cell density at the measured point affected the $440 \mathrm{~nm}$ absorption of the stained and unstained brain similarly. Dye absorption was calculated as the difference between the stained brain and the corrected corresponding blank:

Dye absorption $=$ Total absorption - Corrected blank Corrected blank $440=$ Raw blank $440 \times$ Individual absorption 440/Mean absorption 440

Corrected blank $535=$ Raw blank $535 \times$ Individual absorption 440/Mean absorption 440

Dye absorption 535/440 = Dye absorption 535/ Dye absorption 440 
where mean absorption 440 was calculated as an average of each group.

Dye acid-base titrations were done in brain homogenates at $20^{\circ} \mathrm{C}$. Brain homogenate was prepared by removing the stained whole brain from a dog and homogenizing it in 2 vol of sucrose $0.32 \mathrm{~mol} / \mathrm{L}$. This preparation was further diluted with Ringer's solution 1:15. Changes in $\mathrm{pH}$ were produced by $0.04 \mathrm{~N} \mathrm{NaOH}$ or $\mathrm{HCl}$ and monitored with a calibrated $\mathrm{pH}$ meter (MI-410 pH electrode; Micro-Electrodes, Londonderry, N.H. CG-817 digital pH meter; Schott America, Yonkers, N.Y.) Color transparency photographs of the $\mathrm{pH}$-adjusted homogenates were taken also at $20^{\circ} \mathrm{C}$. A calibration curve was obtained from the differences between the absorption by the stained and blank homogenates, both at 440 and $535 \mathrm{~nm}$. The dye absorption ratio at $535 / 440 \mathrm{~nm}$ was calculated. At $20^{\circ} \mathrm{C}, \mathrm{pH}$ was calculated as follows (Fig. 2):

$$
\mathrm{pH}=11.65-4.3071 \times \text { Dye absorption } 535 / 440
$$

Results were expressed as the mean \pm standard deviation. Variance analysis and Student $t$ test (paired, unpaired) were used for statistical analyses.

\section{Results}

CBF. CBF in the surface of the parietal cortex decreased from $28.9 \pm 9.3$ to $14.6 \pm 6.0 \mathrm{ml} / 100$ $\mathrm{gm} / \mathrm{min}$ during the core cooling (Fig. 3). It was only $0.85 \pm 0.66 \mathrm{ml} / 100 \mathrm{gm} / \mathrm{min}$ during the solitary SVC perfusion but increased to $8.98 \pm 2.02 \mathrm{ml} / 100 \mathrm{gm} /$ min during 90 minutes of retrograde perfusion under the mean driving pressure of $29.69 \pm 9.92 \mathrm{~mm}$ $\mathrm{Hg}$ (group 1: $n=21$ ) between the sagittal sinus and the aorta.

When perfused with a moderate driving pressure of $23.51 \pm 3.04 \mathrm{~mm} \mathrm{Hg}$, the $\mathrm{CBF}$ was $8.37 \pm 1.84$ $\mathrm{ml} / 100 \mathrm{gm} / \mathrm{min}$ in 12 dogs (subgroup 1-A). Although a driving pressure higher than $30 \mathrm{~mm} \mathrm{Hg} \mathrm{(37.93 \pm}$ $9.92 \mathrm{~mm} \mathrm{Hg}$ ) in nine other dogs (subgroup 1-B) elevated the mean CBF $(9.80 \pm 1.95 \mathrm{ml} / 100 \mathrm{gm} /$ min), a decrease in or shut down of $\mathrm{CBF}$ was observed in three of them.

$\mathrm{CBF}$ as a function of driving pressure. The overall cerebral vascular resistance ratio (retrograde/ antegrade) was 1.22 . When the retrograde and antegrade cerebral vascular resistance were compared in individual animals, the mean cerebral vascular resistance during the retrograde cerebral perfusion was $1.21 \pm 0.4$ times that of the antegrade full-flow (100 ml $/ \mathrm{kg} / \mathrm{min})$ perfusion $(n=21$ : group 1) and was $1.45 \pm 0.63$ times that of low-flow ( 25 $\mathrm{ml} / \mathrm{kg} / \mathrm{min}$ ) perfusion ( $n=9$ : subgroup 1-B) (Fig. 4).

Intracellular pH mapping. In group 2, during 60 minutes of circulatory arrest, the $\mathrm{pH}$ decreased to $6.43,6.43,6.40,6.28,6.26,6.24,6.81,5.86$, and 6.51 in the brain surface, anterior cortex, posterior cor-

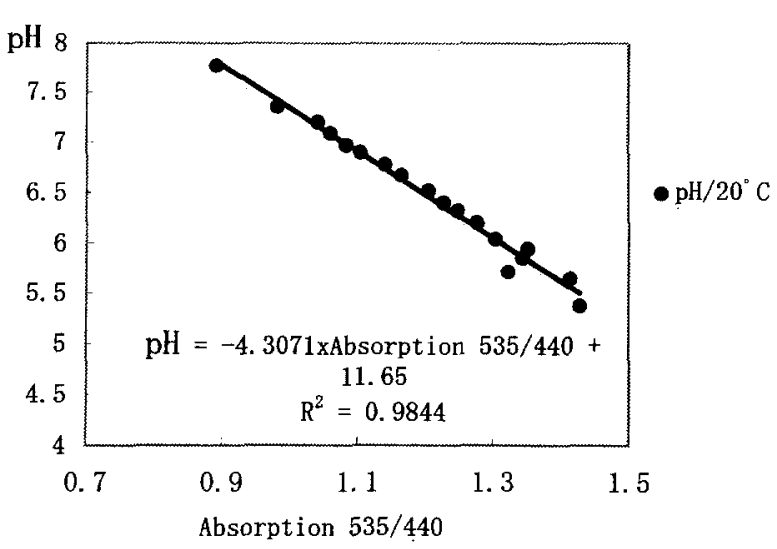

Fig. 2. PH standard curve obtained from $\mathrm{pH}$-adjusted brain homogenate. The relationship between the $\mathrm{pH}$ and the absorption ratio at $535 \mathrm{~nm}$ and $440 \mathrm{~nm}$ was linear.

tex, thalamus, caudal nucleus, hippocampus, pons, cerebellum, and spinal cord, respectively, and further decreased during the following 30-minute evaluation (Fig. 5, Table I).

The $\mathrm{pH}$ (6.64 to 7.29) after 90 minutes of retrograde brain perfusion in group 1 was significantly higher in all parts of the brain-but not the spinal cord-than the $\mathrm{pH}$ at 60 minutes of circulatory arrest; and it was higher in all parts than the $\mathrm{pH}$ at the end of the 30-minute evaluation. In the cerebral slice in group 1, the $\mathrm{pH}$ was significantly higher in the anterior cortex than in the thalamus, caudal nucleus, and hippocampus and lower in the caudal nucleus than in other parts of the cerebrum.

Blood analyses, fluid supplementation, and water content. Table II summarizes the results of blood gas analyses (at $37^{\circ} \mathrm{C}$ ) (Table II), hematocrit level and blood glucose and lactate contents. The perfusate was within the range of $\mathrm{pH}$-stat strategy at the end of the core cooling. The $\mathrm{pH}$ of the perfusate was constant despite the lowered carbon dioxide tension during the retrograde brain perfusion where lactic acidosis gradually developed. Fluid supplementation required was $1140 \pm 580 \mathrm{ml}$ during the retrograde brain perfusion, which decreased the hematocrit level to $16.3 \%$ to $13.8 \%$.

Water contents were $0.774 \pm 0.011$ in the brain and $0.673 \pm 0.014$ in the spinal cord after retrograde perfusion and $0.764 \pm 0.012$ and $0.699 \pm 0.029$, respectively, after the circulatory arrest. The water content in the brains perfused retrogradely was significantly higher than that in the brains after circulatory arrest $(p=0.012)$. Conversely, the water content in the spinal cord perfused retrogradely was 


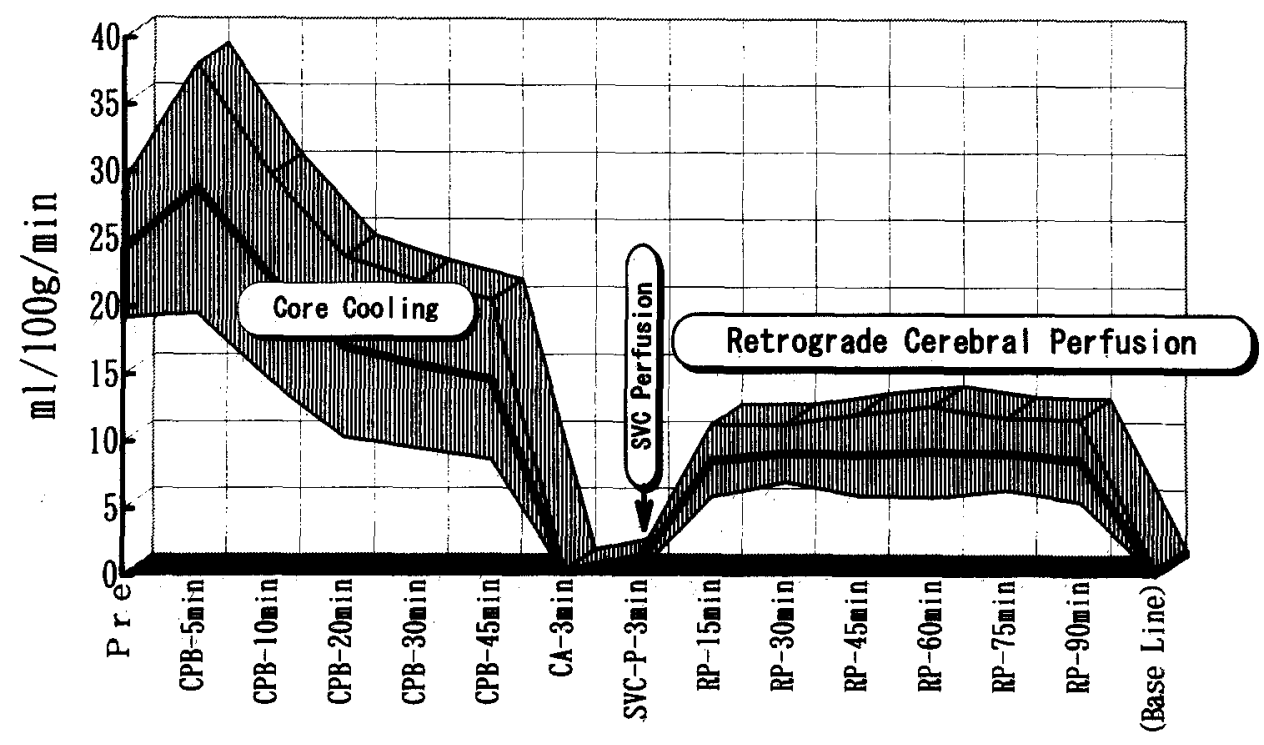

Fig. 3. Cerebral tissue blood flow throughout the experiment in group $1(n=21)$. It was $0.85 \pm 0.66$ $\mathrm{ml} / 100 \mathrm{gm} / \mathrm{min}$ during the solitary perfusion through the SVC. Retrograde perfusion $(R P)$ through the sagittal sinus and the SVC increased the blood flow to a stable value of $8.98 \pm 2.02 \mathrm{ml} / 100 \mathrm{gm} / \mathrm{min}$. $C A$, Circulatory arrest; $S V C-P$, solitary SVC perfusion; $R P$, retrograde brain perfusion.

significantly less than that after circulatory arrest $(p=0.002)$.

\section{Discussion}

Cerebral tissue blood flow in this study was smaller than the values shown by Usui ${ }^{11}$ and Nojima $^{18}$ and their associates in their experimental retrograde cerebral perfusion through the SVC alone ${ }^{10}$ or bilateral maxillar veins ${ }^{11,18}$ but almost the same as the values of antegrade perfusion shown by Mohri and associates. ${ }^{19}$ The laser photometric method, monitoring tissue blood flow in a narrow contact area (hemisphere with diameter of $1 \mathrm{~mm}$ ), occasionally showed an excessively large value when small vasculature was present in the monitored area, especially during retrograde cerebral perfusion. Therefore, we selected an avascular area on the gyrus of the parietal lobe to exclude the effect of dilated veins. This selection may be the cause of the relatively lower value in our study.

We think that the value derived by laser photometry indicates the functional value of tissue blood flow even when the brain receives retrograde perfusion, on the condition that the effect of dilated venous vasculature or venous shunt flow is eliminated as in our study. This method offers continuous measurement of tissue blood flow which facilitates immediate avoidance of any excessive values in blood flow. In contrast, hydrogen gas clearance test does not offer an instant or continuous value, where the nonfunctional blood flow in the dilated veins or venovenous shunt in the measured hemisphere should be unavoidably added as a value of "tissue blood flow" during retrograde brain perfusion.

In the present study, the overall CBF was $8.98 \pm$ $2.01 \mathrm{ml} / 100 \mathrm{gm} / \mathrm{min}$ during the retrograde brain perfusion with a driving pressure of $29.69 \pm 9.92$ $\mathrm{mm} \mathrm{Hg}$. This value was almost the same as our previous data obtained during profoundly hypothermic low-flow perfusion. ${ }^{20}$ Several investigators showed that low-flow perfusion yielded CBF of the same magnitude. ${ }^{21-23}$ Therefore, we believe that retrograde brain perfusion can perfuse and may protect the brain as long as the functioning perfusion pressure is kept above $20 \mathrm{~mm} \mathrm{Hg}$.

Cerebral vascular resistance during retrograde perfusion has been thought to be small. Usui and associates ${ }^{10}$ estimated that it decreased to about half that during antegrade full-flow total perfusion. Nojima and associates ${ }^{18}$ showed that cerebral vascular resistance was slightly less than that shown by Usui and associates. ${ }^{10}$ Their data seem to have been affected by methodologic overestimation of cerebral tissue blood flow during the retrograde perfusion, as they stated. ${ }^{10,18}$

In the present study, the cerebral vascular resistance 


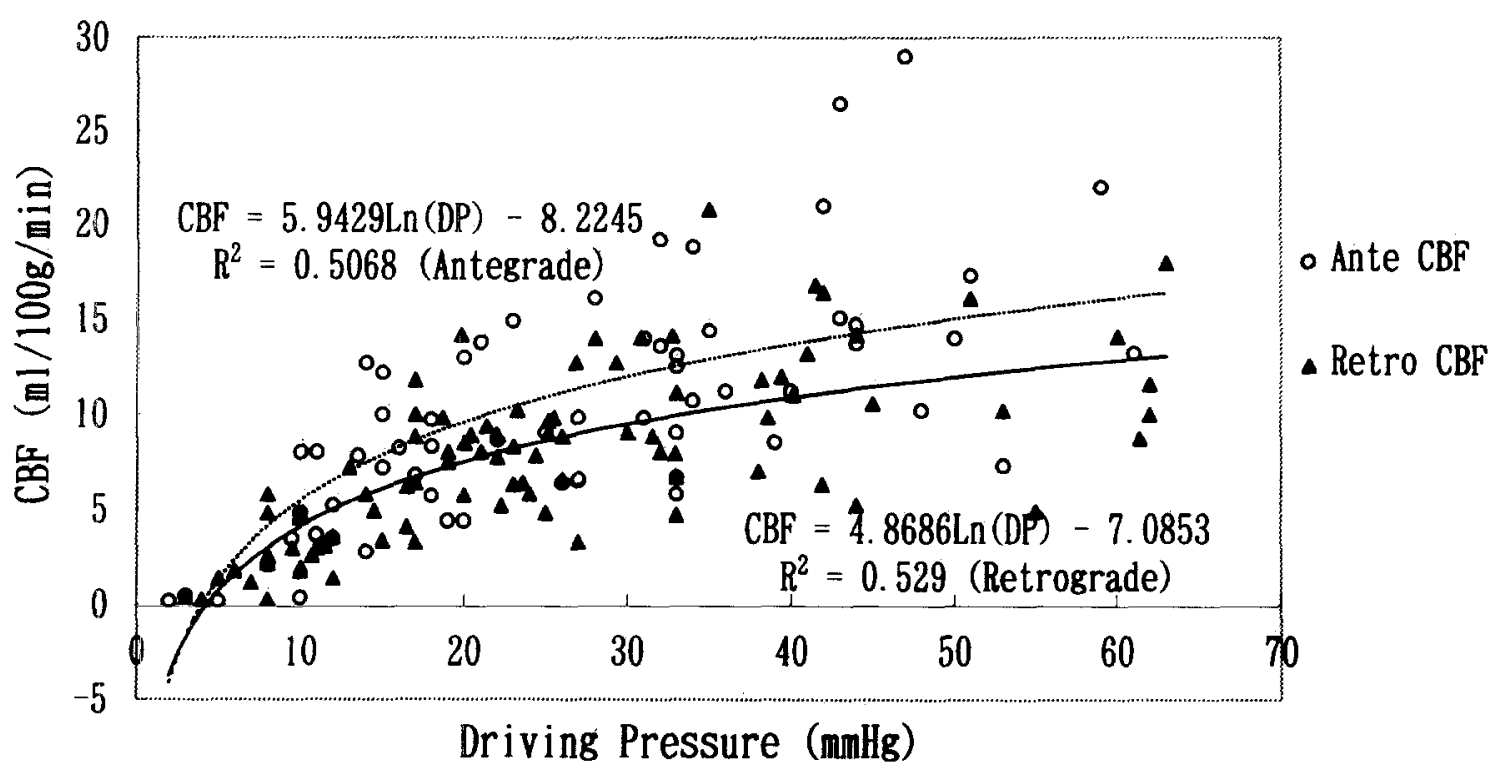

Fig. 4. Cerebral tissue blood flow as a function of driving pressure between the sagittal sinus and the aorta obtained from all 21 dogs in group 1. Antegrade values were obtained at the end of the core-cooling perfusion, also from 21 dogs in group 1 . Ante, Antegrade; Retro, retrograde; $L n$, logarithm (e); $D P$, driving pressure.

was slightly higher when the brain was perfused retrogradely than when perfused antegradely. The perfusion through the sagittal sinus and SVC substantially perfuses the canine brain beyond the venous valves. We directly and continuously measured the functional driving pressure between the sagittal sinus and the aorta, as well as the CBF. The relationship was the same at any pressure. When the driving pressure was set at the same degree, the retrograde cerebral vascular resistance was 1.0 to 1.6 times that of the antegrade cerebral vascular resistance (Fig. 4). However, the hematocrit value and the carbon dioxide tension of the perfusate were lower during the retrograde perfusion than during the core cooling in our study. The lower carbon dioxide tension might have elevated the cerebral vascular resistance during the retrograde perfusion. Also, the lower hematocrit value might have caused underestimation of the CBF because the laser photometric method depends on the movements of the red blood cells in the tissue vasculature.

Considering these conditions, we assume that the cerebral vascular resistance was the same in principle whenever the brain was perfused antegradely or retrogradely. We, therefore, hypothesize that the cerebral capillary bed must be the main determinant of the cerebral vascular resistance during profound hypothermia. The character of the supplying vessels may also affect the additional resistance. The capac-

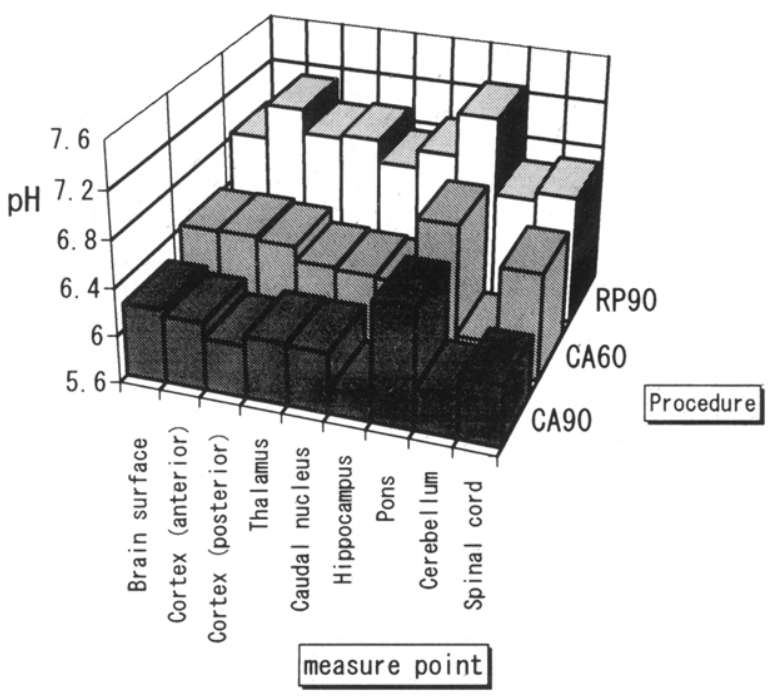

Fig. 5. Regional changes in intracellular $\mathrm{pH}$. The $\mathrm{pH}$ after retrograde brain perfusion were significantly higher than after circulatory arrest. $R P 90$, After 90 minutes of retrograde brain perfusion; $C A 60$, at 60 minutes of circulatory arrest; $C A 90$, at 90 minutes of circulatory arrest.

itance of venous vasculature is far greater than that of arterial vasculature, and the brain is enclosed firmly in the skull. Therefore, perfusion through the veins allows the tissue pressure to increase in parallel with the perfusion pressure as Usuil ${ }^{11}$ and Nojima ${ }^{18}$ 
Table I. Intracellular pH mapping

\begin{tabular}{|c|c|c|c|c|c|}
\hline \multirow[b]{2}{*}{ Measure point } & \multicolumn{2}{|c|}{ Circulatory arrest } & \multirow[b]{2}{*}{ Retrograde perfusion } & \multicolumn{2}{|c|}{$p$ Value $(\mathrm{t}$ test $)$} \\
\hline & 60 minutes & 90 minutes & & $R P / C A 60$ & $R P / C A 90$ \\
\hline Brain surface (in situ) & & & $6.990 \pm 0.390$ & & \\
\hline Brain surface (slice) & $6.426 \pm 0.262$ & $6.219 \pm 0.287$ & $6.840 \pm 0.245$ & 0.00026 & $<0.0001$ \\
\hline Anterior cortex & $6.433 \pm 0.163$ & $6.168 \pm 0.313$ & $7.139 \pm 0.169$ & $<0.0001$ & $<0.0001$ \\
\hline Posterior cortex & $6.403 \pm 0.255$ & $6.043 \pm 0.366$ & $6.932 \pm 0.291$ & $<0.0001$ & $<0.0001$ \\
\hline Thalamus & $6.277 \pm 0.377$ & $6.124 \pm 0.518$ & $6.962 \pm 0.242$ & $<0.0001$ & $<0.0001$ \\
\hline Caudal nucleus & $6.260 \pm 0.381$ & $6.115 \pm 0.408$ & $6.770 \pm 0.203$ & $<0.0001$ & $<0.0001$ \\
\hline Hippocampus & $6.243 \pm 0.247$ & $5.811 \pm 0.566$ & $6.923 \pm 0.283$ & $<0.0001$ & $<0.0001$ \\
\hline Pons & $6.806 \pm 0.395$ & $6.598 \pm 0.517$ & $7.290 \pm 0.280$ & 0.0007 & $<0.0001$ \\
\hline Cerebellum & $5.863 \pm 0.337$ & $5.947 \pm 0.400$ & $6.635 \pm 0.208$ & $<0.0001$ & $<0.0001$ \\
\hline Spinal cord & $6.511 \pm 0.256$ & $6.113 \pm 0.376$ & $6.705 \pm 0.304$ & 0.121 & 0.0003 \\
\hline
\end{tabular}

Data are expressed as mean \pm standard deviation. $R P / C A 60$, Comparison between retrograde brain perfusion and 60 minutes of circulatory arrest; $R P / C A 90$, comparison between retrograde brain perfusion and 90 minutes of circulatory arrest.

Table II. Blood analyses

\begin{tabular}{|c|c|c|c|c|c|}
\hline & Pre & $C P B$ 45min & RP 30min & $R P 60$ min & $R P 90 \min$ \\
\hline $\mathrm{pH}$ & $7.423 \pm 0.103$ & $7.215 \pm 0.090$ & $7.261 \pm 0.133$ & $7.206 \pm 0.150$ & $7.188 \pm 0.161$ \\
\hline $\mathrm{PCO}_{2}(\mathrm{~mm} \mathrm{Hg})$ & $38.35 \pm 11.27$ & $73.28 \pm 15.31$ & $52.26 \pm 14.44$ & $56.30 \pm 17.01$ & $57.33 \pm 17.18$ \\
\hline $\mathrm{PO}_{2}(\mathrm{~mm} \mathrm{Hg})$ & $76.81 \pm 29.40$ & $569.6 \pm 85.5$ & $737.6 \pm 77.0$ & $700.5 \pm 85.6$ & $682.8 \pm 78.5$ \\
\hline Base excess & $0.20 \pm 4.18$ & $0.67 \pm 6.98$ & $-4.52 \pm 4.49$ & $-6.72 \pm 4.91$ & $-7.33 \pm 4.59$ \\
\hline Hemoglobin $(\mathrm{gm} / \mathrm{dl})$ & $16.74 \pm 3.11$ & $9.33 \pm 2.34$ & $6.09 \pm 5.7$ & $5.71 \pm 1.85$ & $5.31 \pm 1.81$ \\
\hline Hematocrit level $(\%)$ & $45.02 \pm 7.75$ & $23.16 \pm 4.38$ & $16.30 \pm 4.43$ & $15.38 \pm 4.20$ & $13.80 \pm 4.12$ \\
\hline Lactate $(\mathrm{mg} / \mathrm{dl})$ & $23.46 \pm 8.67$ & $31.16 \pm 12.70$ & $30.72 \pm 10.33$ & $33.64 \pm 9.85$ & $37.96 \pm 9.37$ \\
\hline Glucose (mg/dl) & $103.3 \pm 34.5$ & $106.6 \pm 32.1$ & $98.5 \pm 39.6$ & $96.1 \pm 40.5$ & $104.4 \pm 46.3$ \\
\hline
\end{tabular}

Data from group $1(n=21)$ are expressed as mean \pm standard deviation $\left(\mathrm{pH}, \mathrm{PCO}_{2}\right.$, and $\mathrm{PO}_{2}$ are the values at $\left.37^{\circ} \mathrm{C}\right)$. Pre, Before CPB; $R P$, retrograde brain perfusion; $\mathrm{PCO}_{2}$, carbon dioxide tension; $\mathrm{PO}_{2}$ oxygen tension.

and their associates showed. Elevated tissue pressure interferes with the tissue perfusion in the brain. The vascular resistance would increase more as the venous perfusion pressure increased. The present data showed that driving pressures above $35 \mathrm{~mm} \mathrm{Hg}$ did not yield expected cerebral tissue blood flow but made the value unstable. The data, we believe, substantiated the physiologic conditions described previously of the artificial retrograde circulation in the brain during profound hypothermia.

Intracellular $\mathrm{pH}$ mapping of the entire brain and the thoracic spinal cord was made by the photometric method of LaManna, with the use of neutral red stain as a $\mathrm{pH}$ indicating vital dye. ${ }^{14-17}$ Some modifications were required to measure the canine brain $\mathrm{pH}$ at $20^{\circ} \mathrm{C}$. The retrograde perfusion maintained intracellular $\mathrm{pH}$ uniformly in all areas of the brain as long as the brain was perfused beyond the venous valves. No signs of perfusion defects were found in the brain. The $\mathrm{pH}$ in the spinal cord was relatively low after the retrograde perfusion, although the experiment was designed to keep the thoracic spinal cord within the perfused area. However, the value was significantly higher than the $\mathrm{pH}$ at 90 minutes of circulatory arrest. This acidosis may be the result of delayed (about 9 minutes) measurement of the spinal cord $\mathrm{pH}$ because the resection of the spinal cord required several additional minutes. Therefore, we think that the thoracic spinal cord was also perfused relatively well in this model.

Few data exist regarding intracellular $\mathrm{pH}$ of the brain during profound hypothermia. Norwood and associates $^{25}$ showed a $\mathrm{pH}$ decline in an isolated brain after brief ischemia. Swain and associates ${ }^{25}$ showed that perfusion at a flow rate of $10 \mathrm{ml} / \mathrm{kg} / \mathrm{min}$ maintained high intracellular $\mathrm{pH}$ in a core-cooled sheep brain. Aoki and associates ${ }^{26}$ and Jonas, ${ }^{27}$ using $\mathrm{pH}$-stat management, showed rapid $\mathrm{pH}$ recovery after 60 minutes of circulatory arrest. Although these ${ }^{31} \mathrm{P}$-nuclear magnetic resonance studies added reliable knowledge of $\mathrm{pH}$ and high-energy phosphates, no data exist on $\mathrm{pH}$ of the brain perfused retrogradely. We believe that the photometric method used in the present study is the most suitable to estimate the protective effect of retrograde brain perfusion because it facilitates $\mathrm{pH}$ mapping in the entire brain.

In conclusion, we believe that the retrograde 
brain perfusion is capable of protecting the entire brain for 90 minutes as long as the driving pressure is maintained adequately and the perfusion is not interfered with by the venous valves. Required driving pressure may be 20 to $30 \mathrm{~mm} \mathrm{Hg}$. It should be further studied whether the retrograde perfusion at a driving pressure below $20 \mathrm{~mm} \mathrm{Hg}$ can protect the brain for 90 minutes because an incomplete perfusion with lower driving pressure may be more harmful than circulatory arrest. ${ }^{28,29}$ Brain edema remains as a next theme of investigation.

In clinical practice, valves in the internal jugular veins must be evaluated early on as to whether they function because the venous valves could alter the functional driving pressure for brain circulation even if the perfusion pressure is elevated. An extremely high perfusion pressure at an ordinary perfusion flow rate suggests that the venous valves are blocking the blood flow to the brain.

We thank Joseph C. LaManna, MD, for his advice on the measurements of the intracellular $\mathrm{pH}$ in the brain and Mr. Mikio Watanabe for his technical support.

\section{REFERENCES}

1. Mills NL, Ochsner JL. Massive air embolism during cardiopulmonary bypass. J Thorac CARDIOVASC SURG 1980;80:708-17.

2. Watanabe T, Shimasaki T, Kuraoka S, et al. Retrograde cerebral perfusion against massive air embolism during cardiopulmonary bypass. J THORAC CARDIOVASC SURG 1992;104:532-3.

3. Lemole GM, Strong MD, Spagna PM, Karmilowicz NP. Improved results for dissecting aneurysms: intraluminal sutureless prosthesis. J THORAC CARDroVASC SURG 1982;83:249-55.

4. Ueda Y, Miki S, Kusuhara K, Okita Y, Tahara T, Yamanaka K. Surgical treatment of aneurysm or dissection involving the ascending aorta and aortic arch, utilizing circulatory arrest and retrograde cerebral perfusion. J Cardiovase Surg 1990;31:553-8.

5. Yamashita C, Nakamura H, Nishikawa Y, Yamamoto S, Okada M, Nakamura K. Retrograde cerebral perfusion with circulatory arrest in aortic arch aneurysms. Ann Thorac Surg 1992;54:566-8.

6. Takamoto S, Matsuda T, Harada M, Miyata S, Shimamura $Y$. Simple hypothermic retrograde cerebral perfusion during aortic arch replacement. A preliminary report on two successful cases. J THORAC CARDIOVASC SURG 1992;104:1106-9.

7. Takamoto S, Matsuda T, Harada M, Shimamura Y, Miyata S. Simple hypothermic retrograde cerebral perfusion during aortic arch surgery. J Cardiovasc Surg 1992;33:560-7.
8. Svensson LG, Crawford ES, Hess KR, et al. Deep hypothermia with circulatory arrest: determination of stroke and early mortality in 656 patients. J THORAC CARDIOVASC SuRg 1993;106:19-31.

9. Safi HJ, Brien HW, Winter JN, et al. Brain protection via cerebral retrograde perfusion during aortic arch aneurysm repair. Ann Thorac Surg 1993;56:270-6.

10. Usui A, Hotta T, Hiroura M, et al. Retrograde cerebral perfusion through a superior vena caval cannula protects the brain. Ann Thorac Surg 1992;53:47-53.

11. Usui A, Oohara K, Liu T-1, Murase M, Tanaka M, Takeuchi E, Abe T. Determination of optimum retrograde cerebral perfusion conditions. J THORAC CARDIOVASC SURG 1994;107:300-8.

12. Usui A, Oohara K, Liu T-1, Murase M, Tanaka M, Takeuchi E, Abe T. Comparative experimental study between retrograde cerebral perfusion and circulatory arrest. J THORAC CARDIOVASC SURg 1994; 107:1228-36.

13. Padget DH. The development of the cranial venous system in man, from the view point of comparative anatomy. Contr Embryo Carneg Inst 1957;36:81-140.

14. Kogure K, Alonso OF, Martinez E. A topographic measurement of brain $\mathrm{pH}$. Brain Res 1980;195:95-109.

15. LaManna JC, McCracken $K$. The use of neutral red as an intracellular $\mathrm{pH}$ indicator in rat brain cortex in vivo. Analyt Biochem 1984;142:117-25.

16. LaManna JC. Intracellular $\mathrm{pH}$ determination by absorption spectrophotometry of neutral red. Metab Brain Dis 1987;2:167-82.

17. Griffith JK, Cordisco BR, Lin CW, LaManna JC. Distribution of intracellular $\mathrm{pH}$ in the rat brain cortex after global ischemia as measured by color film histophotometry of neutral red. Brain Res 1992;573:1-7.

18. Nojima T, Magara T, Nakajima Y; et al. Optimal perfusion pressure for experimental retrograde cerebral perfusion. J Card Surg 1994;9:548-59.

19. Mohri H, Sadahiro M, Akimoto H, Haneda K, Tabayashi K, Ohmi M. Protection of the brain during hypothermic perfusion. Ann Thorac Surg 1993;56:1493-6.

20. Watanabe T, Washio M. Pulsatile low-flow perfusion for enhanced cerebral protection. Ann Thorac Surg 1993;56:1478-81.

21. Halley MM, Reemtsma K, Creech O Jr. Cerebral blood flow, metabolism, and brain volume in extracorporeal circulation. J THORAC Cardiovasc SuRG 1958;36:506-18.

22. Miyamoto K, Kawashima Y, Matsuda H, et al. Optimal perfusion flow rate for the brain during deep hypothermic cardiopulmonary bypass at $20^{\circ} \mathrm{C}$. An experimental study. J Thorac CARdiovasc Surg 1986;92:1065-70.

23. Govier A, Reves JG, McKay RD, et al. Factors and their influence on regional cerebral blood flow during nonpulsatile cardiopulmonary bypass. Ann Thorac Surg 1984;38:592-600.

24. Norwood WI, Norwood CR, Ingwall JS, Castaneda AR, Fossel ET. Hypothermic circulatory arrest: 31- 
Phosphorus nuclear magnetic resonance of isolated perfused neonatal rat brain. J THORAC CARDIOVASC SURG 1979;78:823-30.

25. Swain JA, McDonald TJ Jr, Griffith PK, Balaban RS, Clark RE, Ceckler T. Low-flow hypothermic cardiopulmonary bypass protects the brain. J THORAC CARDIOVASC SURG 1991;102:76-84.

26. Aoki M, Nomura F, Stromski ME, et al. Effects of $\mathrm{pH}$ on brain energetics after hypothermic circulatory arrest. Ann Thorac Surg 1993;55:1093-103.
27. Jonas RA. Review of current research at Boston Children's Hospital. Ann Thorac Surg 1993;56:1467-72.

28. Scheller MS, Branson PJ, Cornacchia LG, Alksne JF. A comparison of the effects on neuronal Golgi morphology, assessed with electron microscopy, of cardiopulmonary bypass, low-flow bypass, and circulatory arrest during profound hypothermia. J THORAC CARDIOVASC SURG 1992;104:1396-404.

29. Watanabe T, Washio M. Cerebral cellular response to profound hypothermia. Cardiol Young 1993;3:383-93. 